\title{
Perspectives on differing health outcomes by city: accounting for Glasgow's excess mortality
}

\author{
This article was published in the following Dove Press journal: \\ Risk Management and Healthcare Policy \\ 17 June 2015 \\ Number of times this article has been viewed
}

\section{Simon DS Fraser \\ Steve George}

Academic Unit of Primary Care and Population Sciences, Faculty of Medicine, University of Southampton, Southampton, Hampshire, UK

Correspondence: Simon DS Fraser; Steve George

Academic Unit of Primary Care and Population Sciences, Faculty of Medicine, University of Southampton, South Academic Block, Southampton General Hospital, Tremona Road, Southampton SOI6 6YD, Hampshire, UK

Tel +44238I206530

Email s.fraser@soton.ac.uk; pluto@ soton.ac.uk
Abstract: Several health outcomes (including mortality) and health-related behaviors are known to be worse in Scotland than in comparable areas of Europe and the United Kingdom. Within Scotland, Greater Glasgow (in West Central Scotland) experiences disproportionately poorer outcomes independent of measurable variation in socioeconomic status and other important determinants. Many reasons for this have been proposed, particularly related to deprivation, inequalities, and variation in health behaviors. The use of models (such as the application of Bradford Hill's viewpoints on causality to the different hypotheses) has provided useful insights on potentially causal mechanisms, with health behaviors and inequalities likely to represent the strongest individual candidates. This review describes the evolution of our understanding of Glasgow's excess mortality, summarizes some of the key work in this area, and provides some suggestions for future areas of exploration. In the context of demographic change, the experience in Glasgow is an important example of the complexity that frequently lies behind observed variations in health outcomes within and between populations. A comprehensive explanation of Glasgow's excess mortality may continue to remain elusive, but is likely to lie in a complex and difficult-to-measure interplay of health determinants acting at different levels in society throughout the life course. Lessons learned from the detailed examination of different potentially causative determinants in Scotland may provide useful methodological insights that may be applied in other settings. Ongoing efforts to unravel the causal mechanisms are needed to inform public health efforts to reduce health inequalities and improve outcomes in Scotland.

Keywords: Glasgow effect, mortality, inequalities, determinants

\section{Introduction}

From a global perspective, the early part of the 21 st century has seen a significant turning point in population distribution. According to World Health Organization (WHO) estimates, in 1990, less than $40 \%$ of the world's population were living in cities compared to over half by $2010 .{ }^{1}$ This rapid transition is having fundamental implications for health and health inequalities. In Europe, unlike other major world regions, the overall population is predicted to fall. ${ }^{2}$ Low fertility rates, decreasing premature mortality rates, and flattening trends in immigration are leading to an older population profile. ${ }^{2}$ Along with these important demographic changes, wide variations are seen across Europe in health-related behaviors (such as smoking and alcohol consumption) and health outcomes (such as prevalence of long-term conditions and mortality) both between and within countries. Life expectancy at birth and mortality rates, for example, have been shown to vary considerably between different European countries, regions, and cities. ${ }^{3}$ 
Scotland's relatively poor health profile, compared with other parts of the United Kingdom and Europe, has been recognized for some considerable time. In 1989, Carstairs and Morris examined the difference between mortality experience in Scotland, England and Wales and suggested that the excess mortality in Scotland may be explained by more adverse conditions (ie, greater deprivation) but were unable to demonstrate a causal relationship. ${ }^{4}$ Such observations led to the concept of a "Scottish effect" in which Scotland was observed to experience an excess of poor health outcomes greater than that which could be explained by variation in common factors such as differences in age distribution. ${ }^{5}$ This led public health leaders to call for a "step change" in societal efforts to improve health in Scotland ${ }^{6}$ However, the optimal targeting of such efforts and their effectiveness in narrowing inequalities may have been somewhat hindered by uncertainty about true causal mechanisms.

Newer techniques, such as multilevel modeling, have allowed for better understanding of the nature of associations (such as that between deprivation and diet), but have also resulted in greater awareness of the lack of simplistic explanations. For example, improved ability to compare the relationship between Scottish health behaviors and associated outcomes has meant that the role of deprivation as the sole explanatory factor has been questioned. ${ }^{7}$ Similarly, better understanding of factors such as the apparent change in the influence of socioeconomic status over time (when compared with the rest of Great Britain) has revealed a greater underlying degree of complexity than was previously appreciated. ${ }^{8,9}$

Leading on from the identification of the variation between Scotland and the rest of the UK, the Glasgow Centre for Population Health (GCPH) has been in the forefront of work identifying that several health outcomes and health-related behaviors are worse in particular areas within Scotland, particularly West Central Scotland (including Greater Glasgow), and are improving at a slower rate than comparable, postindustrial regions in Europe and the rest of Scotland. ${ }^{8,10-12}$ Yet, despite a growing body of research in this area, a comprehensive explanation for Glasgow's excess mortality has continued to prove elusive. This effect has sometimes been referred to as "the Glasgow effect", although the term is considered by some to be unhelpful. The excess appears to be increasing over time, is seen for many different causes of death, is seen in comparison of all social classes (although for premature mortality, the excess is greatest in comparisons of those living in the poorest areas), and has been observed in all parts of Scotland when compared to other areas, not just Glasgow.
This review does not aim to represent a complete synopsis of all work in this area, but to describe some of the studies that have been key in shaping our understanding of the excess mortality in Scotland and, more specifically, in Glasgow, to summarize current thinking in the light of more recent work, and to identify where uncertainties remain that may require future investigation.

\section{Deprivation and health in Scotland}

In 2005, Hanlon et al published the findings of a crosssectional analysis of the British population using data from the 1981, 1991, and 2001 censuses, demonstrating that, between 1981 and 2001, Scotland became less deprived relative to the rest of Great Britain but that age and sex standardized all-cause mortality rates were $12 \%$ higher in Scotland in 1981 and $15 \%$ higher in $2001 .{ }^{8}$ From their findings, they also suggested that measures of deprivation (using the Carstairs score - a measure of area-based deprivation based on four variables - adult male unemployment, lack of car ownership, low social class, and overcrowding $)^{13}$ did not explain most of the higher mortality in Scotland (Table 1). ${ }^{8}$

Subsequently, in 2007, analyses of combined data from Scottish Health Surveys in 1995, 1998, and 2003 (nationally representative population surveys, total $n=25,127$ ) showed that, by comparison with the rest of Scotland, men in Greater Glasgow had higher mortality rates from cancer, chronic liver disease, and drug-related mental health disorders even after adjustment for area deprivation (also using the Carstairs index). In considering these findings, it is important to remember that identifying excess mortality in Glasgow relative to the rest of Scotland may be challenging, given that Scotland already exhibits an excess in relation to other areas. Higher rates of acute sickness, potential psychiatric morbidity, and long-standing illness (in men) also remained after adjustment for socioeconomic factors in this study as did some behavioral factors, such as poor diet (low green vegetable consumption) in men. Higher rates of excess alcohol consumption and binge drinking were found in both deprived and nondeprived areas of Glasgow compared with the rest of Scotland even after adjustment for age, survey year, and socioeconomic status. Interestingly, differences in some other behavioral factors, such as smoking and using additional salt (in men), did appear to be explained by socioeconomic status. ${ }^{11}$

In 2008, Gray et al ${ }^{12}$ reported a similar study, but with comparison of Glasgow broadened to include a variety of European countries and regions (total $n=101,923$, of whom 1,267 were participants of the 2003 Scottish Health Survey 


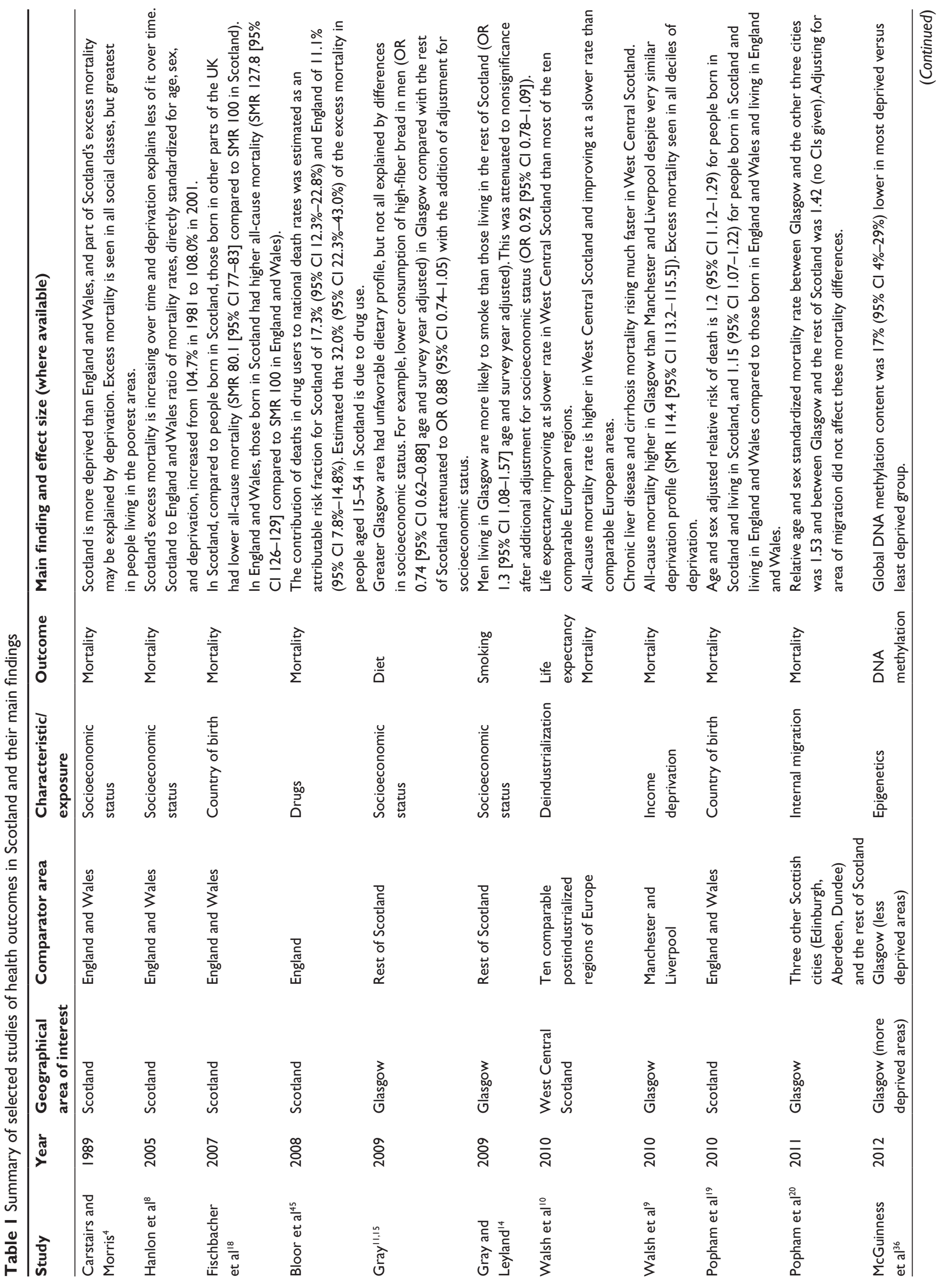


resident in Greater Glasgow). Again, the research question of interest was the degree to which socioeconomic factors (this time using occupational status and educational attainment as more internationally comparable measures) explained differences in health behaviors and outcomes. The authors found that Greater Glasgow had a comparable socioeconomic profile in terms of occupation-based social class to many of its European counterparts, though conceded there were some differences in profile in terms of education status (with a higher proportion with no qualifications in Glasgow). After adjustment for age, social class, and education qualification, binge drinking, smoking (in both men and women), obesity, diabetes, self-reported poor health, acute sickness, longstanding illness, and psychological morbidity tended to all be higher in Glasgow than in other regions, though the picture was slightly mixed (with some similarities with other areas for certain behaviors and outcomes). In this study, they also concluded that the variations they had observed could not be explained solely by socioeconomic deprivation. ${ }^{12}$

In 2009, Gray and Leyland then published a study looking specifically at variations in smoking behavior. Using data from three Scottish Health Surveys again $(1995,1998$, and 2003, total $n=25,127$ ), they compared smoking behavior between Greater Glasgow and the rest of Scotland. For both men and women, the likelihood of smoking was considerably higher in Glasgow than in the rest of Scotland (odds ratio [OR] $1.30,95 \%$ confidence interval $[\mathrm{CI}]=1.08-1.56$ and OR $1.43,95 \% \mathrm{CI}=1.22-1.68$, respectively). Crucially, the detailed nature of these surveys had allowed for four measures of socioeconomic status to be considered (including both individual and area measures): the Carstairs index, occupation-based social class, educational attainment, and economic activity. With this richer definition of social class than could be attained in other studies using fewer measures, they were able to demonstrate that higher rates of smoking in Greater Glasgow were attributable to the social pattern of smoking and lower socioeconomic status, with associations attenuated to statistical nonsignificance after adjustment (Table 1). ${ }^{14}$ This is an important finding, perhaps demonstrating that other measures of deprivation suffer a flooring effect, that is, that these deprivation measures have a lower limit to the data values they can specify. At a very similar time, they reported on a further analysis (also using the same three Scottish Health Surveys) that compared dietary habits in Glasgow with those in the rest of Scotland. They found that certain dietary habits (such as lower consumption of high-fiber bread and potatoes/pasta/rice in Glasgow) were also explained by socioeconomic factors. Other factors (such 
as higher butter and salt consumption in women), however, were not, which hints once again at the complexity of such relationships and their measurement. They concluded that much of the tendency of people in Glasgow to have a poorer diet was explained by socioeconomic factors, although acknowledged the limitations of the study, particularly the use of self-completed questionnaires to assess diet and differential nonresponse rates by social class (Table 1). ${ }^{15}$

In 2009, Walsh et al ${ }^{10}$ compared mortality trends in Scotland with ten other postindustrial regions of Europe (using a variety of different data sources depending on the region). This was an important study given the proposal that deprivation, driven by the underlying effects of deindustrialization, may have been the main driver of poor health in Scotland. They found that mortality trends in West Central Scotland compared badly with other, similar, postindustrial regions of Europe (including some Eastern European regions with high levels of poverty). They therefore challenged the notion that postindustrial decline alone could be implicated (Table 1). ${ }^{10}$ Subsequent to this, in a study comparing mortality (using standardized mortality ratios [SMRs]) by levels of income deprivation at small area level in Glasgow (350 merged data zones with average 750 people per data zone) with the same data for Liverpool and Manchester (291 and 259 Lower Super Output Areas [LSOA], respectively, with average 1,500 people per LSOA), they identified that Glasgow's mortality rates, particularly premature mortality, were significantly higher than those of Liverpool and Manchester even after adjusting for income deprivation. They identified that a high proportion of the excess premature mortality in Glasgow was related to alcohol and drugs, and concluded that, if deprivation alone does not completely explain the increased mortality experience of Glasgow, other explanations such as the possibility of an "extreme" behavioral risk profile in Glasgow should be explored (Table 1). ${ }^{9}$

Taken together, these studies created a mixed picture of the relationship between deprivation, health behaviors, and health outcomes in Glasgow compared to other areas and began to reveal that the underlying explanation was unlikely to be straightforward. The later studies seemed to suggest that more complete measures of socioeconomic status went further in being able to explain some of the observed variation, raising the possibility that simpler measures lacked the breadth or granularity to be able to discriminate true variation, particularly when also assessing the influence of complex variables such as diet. A review of the 2010 Walsh paper written by the second author (SG) picked up on this point, suggesting that existing measures of deprivation may not be comprehensive enough to pick up variation at extremes, such as might be present in Glasgow. It also suggested that other, potentially more "hidden" (and certainly challenging to measure) factors, such as sectarianism, might play a hidden part in explaining some of the differences. ${ }^{16}$

To investigate this further, a study using 2008 and 2009 Scottish Health Survey data ( $\mathrm{n}=13,996$ adults of whom 3,242 were residents of Greater Glasgow) was conducted for the Scottish Government to update and extend the studies that had used the 1995, 1998, and 2003 Scottish Health Surveys. Among its extensive findings, this showed that, when area and individual-level measures of socioeconomic status were combined (area socioeconomic status using the Scottish Index of Multiple Deprivation, individual socioeconomic status using income-related benefits, National Statistics Socioeconomic Classification [a measure of occupational status], economic activity [eg, in paid employment], educational attainment, housing tenure, and marital status), socioeconomic status explained most of the differences in health behaviors and outcomes. However, there were a couple of important exceptions: heart attack (doctor diagnosed) and anxiety that were not explained by socioeconomic differences. ${ }^{17}$

Although this study seems to have clarified a great deal by using even more detailed definitions of socioeconomic status, questions still remained. In the meantime, other groups had been studying a variety of other potential explanatory factors such as ethnicity and migration effects.

\section{Ethnicity and migration}

Fischbacher et $\mathrm{al}^{18}$ used mortality data from 362,029 deaths in Scotland to examine whether country of birth was linked to differences in mortality experience. They identified only small excess cardiovascular mortality among people born in India, Pakistan, Bangladesh, and Ireland compared to people born in Scotland, but significantly greater mortality differences among South Asians when compared with residents of England and Wales (Table 1). ${ }^{18}$ Their findings highlighted the differences in mortality between Scotland and England and Wales for people of non-Scottish birth, but did not suggest that ethnicity alone would explain these differences.

Following this, in 2010, using mortality data from the England and Wales Office for National Statistics and the General Register Office for Scotland along with census data, Popham et $\mathrm{al}^{19}$ compared mortality differences between Scotland and England and Wales according to country of birth and country of residence. They found that, for people living in Scotland ( $n=3.3$ million), risk of death was higher for those born in Scotland ( $\mathrm{n}=3.0$ million) than those born 
in England and Wales $(n=332,255)$. For people living in England and Wales ( $n=32$ million), those born in Scotland $(n=719,199)$ had a higher mortality rate than those born in England and Wales ( $n=31.2$ million). They concluded that country of birth may be a more important determinant of Scotland's adverse outcomes than country of residence and suggest that early life factors may therefore be important in determining excess Scottish mortality (Table 1). ${ }^{19}$

In 2011, focusing more on Glasgow's excess mortality, Popham et $\mathrm{al}^{20}$ conducted another interesting analysis of data from the Scottish Longitudinal Study (an anonymous representative sample of the Scottish population $[n=137,073]$ linking 1991 and 2001 census records with health records and other events data), in which they explored whether the excess mortality rate in Glasgow compared with the rest of Scotland (not fully explained by socioeconomic status) could be explained by selective migration. Selective migration is a net movement of people who are better off and healthier away from areas that are relatively more deprived. They compared migration from one area to another (from 1991 to 2001) between three areas: Glasgow, the next three largest Scottish cities (Edinburgh, Aberdeen, and Dundee), and the rest of Scotland. Their outcome of interest was age and sex standardized mortality rates. They found that, although Glasgow lost a significant proportion of its population between 1991 and 2001 (which was more than the other three cities), this migration difference did not seem to account for differences in mortality rates between the areas (Table 1). ${ }^{20}$

\section{Current thinking}

Given the complexity of the problem, and the seeming lack of a single simple solution, in 2011 the GCPH published an extensive literature review that tried to capture all of the different hypotheses that had been put forward to date to explain Scotland's (and Glasgow's) excess mortality. The review used Bradford Hill's viewpoints on causality to try and evaluate how well each theory explained the mortality trends (Figure 1). ${ }^{21}$ They synthesized the theories into 17 separate potential mechanisms (Figure 2) and identified outstanding research questions for each. ${ }^{22}$ This review provided a comprehensive summary of the literature and a critical review of the strength of evidence for each hypothesis. Its findings and recommendations for future research form a very useful starting point for investigators interested in this area. The authors suggested that each of the hypotheses identified may form part of the explanation for Scotland's mortality pattern but that some, such as inequalities and health behaviors, were

\begin{tabular}{|l|}
\hline 1. Strength of association \\
2. Consistency \\
3. Specificity \\
4. Temporality \\
5. Biological gradient \\
6. Plausibility \\
7. Coherence \\
8. Experiment \\
9. Analogy \\
\hline
\end{tabular}

Figure I Bradford Hill's viewpoints on causality.

likely to constitute a greater component of the causal pathway than others (Figures 3 and 4). They concluded that no single "cause" was likely to fully explain the phenomenon but that the strongest individual candidates were negative health behaviors linked to cultural context. ${ }^{22}$ They commented that the divergence in mortality experience from European counterparts predominantly occurred from 1950 onward. They also grouped possible explanatory factors into "downstream" (such as greater exposure to negative health behaviors), "midstream" (such as some of the cultural factors), and "upstream" (such as poverty and unemployment) with greater or lesser degrees of likelihood (according to Bradford Hill). ${ }^{22}$

1. Deprivation
2. Migration
3. Genetic differences
4. Health behaviors
5. Individual values
6. Different culture of substance misuse
7. Culture of boundlessness and alienation
8. Family, gender relations, and parenting differences
9. Lower "social capital"
10. Sectarianism
11. Culture of limited social mobility
12. Health service supply and demand
13. Depriving concentration "area effects"
14. Greater inequalities
15. Deindustrialization
16. Political attack
17. Climatic differences

Figure 2 Hypotheses with the potential to explain/partially explain the Scottish effect identified in the GCPH review.

Note: Copyright (C) 2011. Adapted from McCartney G, Collins C, Walsh D, Batty D. Accounting for Scotland's Excess Mortality: Towards a Synthesis. Glasgow: Glasgow Centre for Population Health. Available from: http://www.gcph.co.uk/ publications/238accounting_for_scotlands_excess_mortality_towards_a_synthesis. ${ }^{22}$ Abbreviation: GCPH, Glasgow Centre for Population Health. 


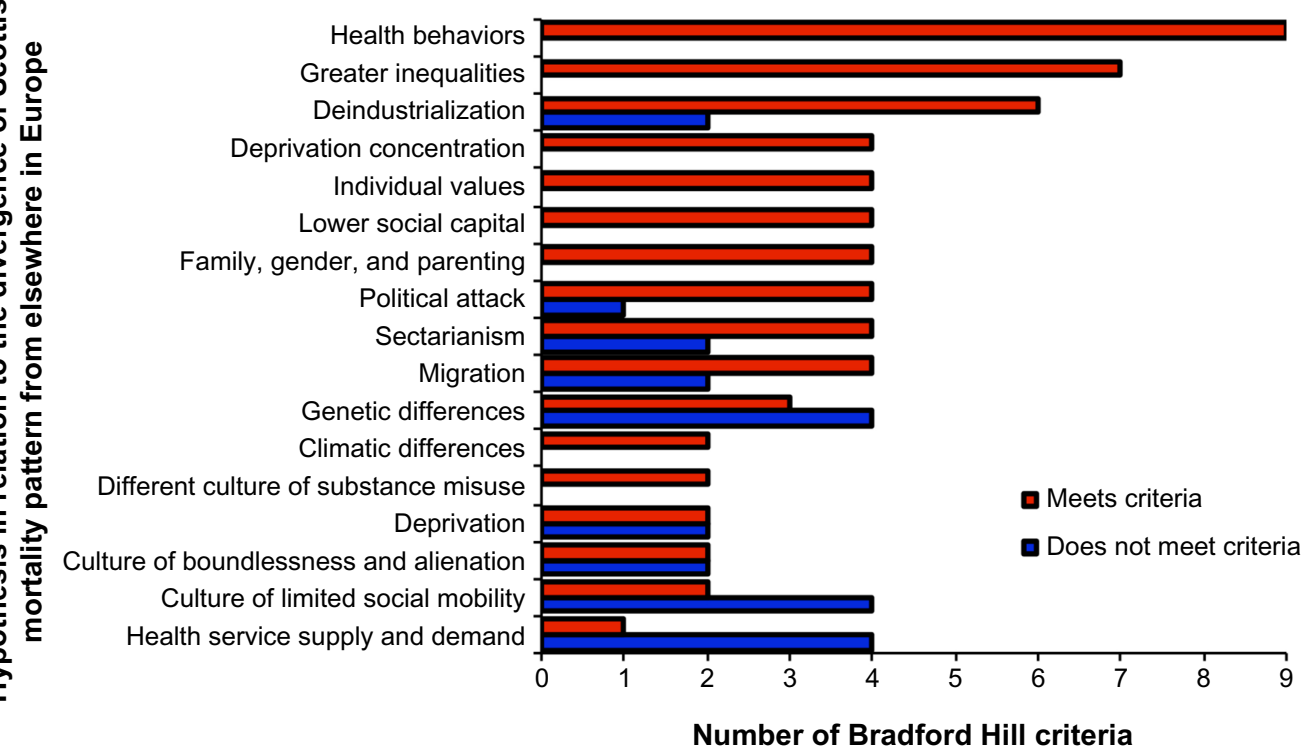

Figure 3 The number of Bradford-Hill's viewpoints met by each hypothesis for the divergence of the Scottish mortality pattern from the rest of Europe in the middle of the 20th century.

Note: Copyright @ 20II. Reproduced from McCartney G, Collins C, Walsh D, Batty D. Accounting for Scotland's Excess Mortality: Towards a Synthesis. Glasgow: Glasgow Centre for Population Health. Available from: http://www.gcph.co.uk/publications/238accounting_for_scotlands_excess_mortality towards_a_synthesis. ${ }^{22}$

In considering the GCPH review, it is worth remembering that, though widely used in this way, the use of Bradford Hill "criteria" as a checklist for evaluating whether a reported association might be causal has been criticized in the past, particularly by Rothman, who felt that the Bradford Hill "criteria" do not clearly distinguish causal from noncausal relations (hence the term "viewpoints" used here, rather than "criteria"). ${ }^{23}$ In the GCPH review, they did, however, provide a useful framework within which to consider the different hypotheses and may help to tease out where ongoing uncertainties remain, and the authors recognized that their conclusions were hindered by a lack of empirical data for many of the hypotheses that were considered.

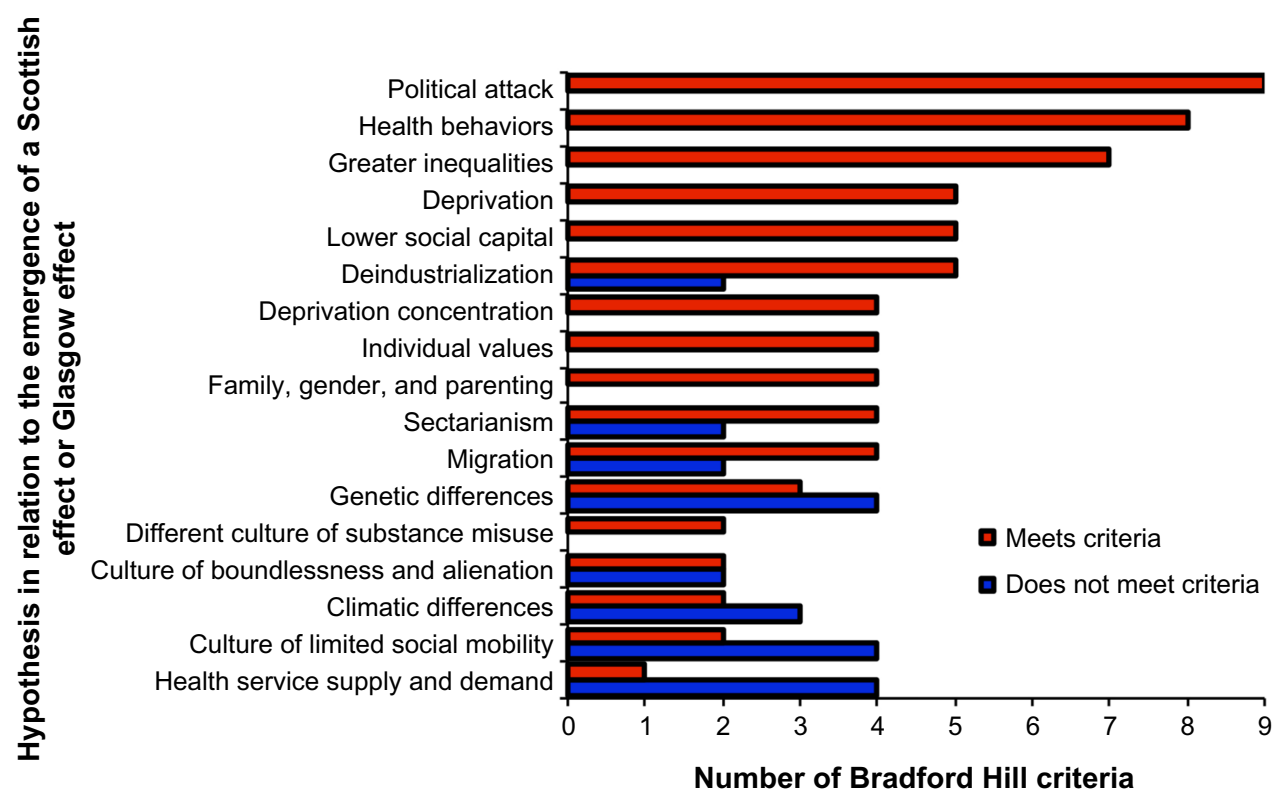

Figure 4 The number of Bradford-Hill's viewpoints met by each hypothesis as explanatory factors in Scotland and Glasgow's excess mortality.

Note: Copyright @ 20 I I. Reproduced from McCartney G, Collins C, Walsh D, Batty D. Accounting for Scotland's Excess Mortality: Towards a Synthesis. Glasgow: Glasgow Centre for Population Health. Available from: http://www.gcph.co.uk/publications/238accounting_for_scotlands_excess_mortality_towards_a_synthesis. ${ }^{22}$ 
Of the hypotheses shown in Figure 2, the most striking is perhaps "political attack". This has been described as the adverse neoliberal influence on the organized working class implemented by the post-1979 UK Conservative governments. ${ }^{24}$ While difficult to immediately understand the connection with health outcomes, it has been argued that the effects of political forces on social inequalities, for example, are often underestimated and have a significant effect on health. ${ }^{25}$ There is no doubt that political influence was closely linked to the profound degree of deindustrialization occurring in the region in the late 1970s and early 1980s, the same time that Glasgow's excess mortality was starting to emerge. ${ }^{26}$ Rapid loss of employment with associated increase in poverty and reduction in council housing was particularly intense in Glasgow and such change may well have had profound effects on health, both in the short term and reaching far into the future as successive generations are affected by the legacy of that period across their lifetime. ${ }^{24}$

Since the GCPH review, other theories of interest have emerged in this field such as the importance of neighborhood context. Research questions identified in the GCPH review (such as "Is there a difference in the geographical patterning of deprivation between Glasgow, Scotland, and other populations - either now, or in the past, and is this associated with mortality patterns?") have led to some innovative research in subsequent years. ${ }^{22}$ Work assimilated by Chandola from a symposium in 2011 included examination of the effects of variation in the spatial distribution of urban populations and their link to health outcomes. ${ }^{27}$ Livingston presented a study at this symposium comparing Glasgow with Liverpool and Manchester, which looked at contextual data at the neighborhood level (as well as deprivation) to show differences in the way in which deprived neighborhoods were arranged, either clustered around the city center as in Liverpool and Manchester, or spread, as in Glasgow. He concluded that the "surrounding deprivation of a neighborhood" has an impact on mortality within a neighborhood. ${ }^{27}$ However, in a subsequent paper with more detailed analyses of this potential effect, despite the more dispersed pattern of deprivation in Glasgow, Livingston and Lee conclude that patterning was not a major contributor to mortality in Glasgow as a similar effect is seen in Liverpool which has a different spatial distribution of deprivation. ${ }^{28}$ This does, however, still suggest a greater degree of complexity to the impact of deprivation than would be detected by, for example, measuring area deprivation alone. It is an example of how, in trying to fully explain Glasgow's excess mortality, consideration may need to be given to much more difficult-to-measure issues, such as the way in which cities are constructed and change over time, and the relationship between this and health outcomes. A more recent study by Taulbut et al, for example, examined subregional spatial inequalities in 160 districts within selected similarly deindustrialized European regions (of which 22 were in West Central Scotland) and showed different patterns of life expectancy, with larger intraregional difference in life expectancy seen in West Central Scotland, suggesting that there may yet be more to explore in this area. ${ }^{29}$

Other more recent studies arising from the research questions identified in the GCPH review has included work on vitamin D deficiency, sectarianism, childhood and early-years influences, and sense of cohesion (and there is ongoing work on the role of social capital). Among these are a systematic review and meta-analysis of studies investigating the link between low vitamin D and premature mortality, in which Rush et al identified that low vitamin D was associated with an increased all-cause mortality risk (hazard ratio [HR] 1.19, 95\% CI 1.12-1.27) in adjusted models and recommended the need for further research in this area. ${ }^{30}$ Graham et al compared Glasgow with Belfast - a similar postindustrial city with a stronger history of sectarianism. They concluded that, with this stronger history, if sectarianism were an important factor in explaining excess mortality in Glasgow, it is likely that similar findings would be seen in Belfast. ${ }^{31}$ Taulbut et al studied two British birth cohorts looking for evidence of a link between adverse childhood experience and mortality. They concluded that there was no evidence for an increased risk of adverse childhood events in Scotland compared with England (and specifically between Glasgow and the Clyde Valley and Merseyside and Greater Manchester), this reducing the likelihood of such adverse events being linked to excess mortality. ${ }^{32}$ Walsh et al applied a "sense of cohesion" measure to a representative sample of adults in Glasgow, Liverpool, and Manchester and identified that sense of cohesion was higher in Glasgow, making it an unlikely candidate to explain Glasgow's excess mortality. ${ }^{33}$

\section{Glasgow's excess mortality in the context of determinants of health}

Seminal work by Dahlgren and Whitehead in 1991 described a model of determinants of health that included "general socioeconomic, cultural, and environmental conditions" as an outer layer influencing the material and social conditions in which people live (education, work environment, health services, and so on), which in turn influences social and community networks and individual lifestyle factors. ${ }^{34}$ They recognized that "the age, sex, and genetic make-up of each individual also plays a part, of course, but these are fixed factors over 
which we have little control". ${ }^{34}$ As with the "downstream", "midstream", and "upstream" factors described in the GCPH review, the hypotheses that have been explored in attempts to explain Glasgow's excess mortality in Figure 2 may be usefully considered in the context of the Dahlgren and Whitehead model. Moreover, the hypotheses summarized in the GCPH review could be thought of as applying at various levels. For example, "a different culture of substance abuse" may be considered to have influence on "general socioeconomic, cultural, and environmental conditions", perhaps affecting societal opinions and actions at the macro level (and thereby impacting a wide range of attitudes, policy, and funding decisions, for example), but also at the level of "individual lifestyle factors" affecting personal behavior (Table 2). Considering both concepts in tandem may help to identify unexplored areas in the investigation of cause, as shown in the table. Although beyond the remit of this paper to describe in detail, an area that, to our knowledge, is underexplored as a potential explanatory factor in Scotland is epigenetics. Rapid developments in the field are identifying potentially important links between smoking, DNA methylation, and cardiovascular disease, for example, and merit further investigation given the degree of unexplained excess mortality. ${ }^{35}$ Findings from the 239 people in the "psychological, social, and biological determinants of ill health (pSoBid)" cohort in Glasgow identified associations between DNA methylation and socioeconomic status and lifestyle factors. ${ }^{36} \mathrm{An}$ important recent study is that by McCartney et al, which examined mortality differences between Scotland and England by pooling 18 nationally representative observational studies (total $n=222,829$ ). They showed that only a quarter of the excess mortality in Scotland could be explained by factors such as socioeconomic status and differences in health behaviors. ${ }^{37}$ This may tempt some to adopt a somewhat fatalistic view of Scotland and Glasgow's excess mortality if it gives the impression that "little can be done about it". We would argue, however, that it strengthens the argument, not only for further exploration of causality, but for adopting a proactive approach in public health terms, as it underlines that there is still much that can be done. Their finding, for example, that alcohol-related mortality is much higher in Scotland, even after adjustment for age, sex, and socioeconomic factors (HR 4.64, 95\% CI 3.55-6.05), demonstrates the vital, ongoing role for public health in Scotland in addressing cultural and behavioral change around substance misuse. ${ }^{37}$

Table 2 Potential links between Dahlgren and Whitehead determinants and Glasgow Centre for Population Health review hypotheses with some suggested areas of future potential exploration

\begin{tabular}{|c|c|c|}
\hline $\begin{array}{l}\text { Dahlgren and Whitehead } \\
\text { determinants }^{34}\end{array}$ & GCPH review hypotheses ${ }^{22}$ & $\begin{array}{l}\text { Potentially underexplored areas that } \\
\text { may impact health outcomes }\end{array}$ \\
\hline $\begin{array}{l}\text { General socioeconomic, } \\
\text { cultural, and environmental } \\
\text { conditions }\end{array}$ & $\begin{array}{l}\text { - Culture of boundlessness and alienation } \\
\text { - Culture of limited social mobility } \\
\text { - Sectarianism } \\
\text { - Greater inequalities } \\
\text { - Deindustrialization } \\
\text { - Political attack } \\
\text { - Climatic differences } \\
\text { - Different culture of substance misuse }\end{array}$ & $\begin{array}{l}\text { - Education provision, structure, and opportunity } \\
\text { - Culture of nihilism and cynicism } \\
\text { - Conflict } \\
\text { - Epigenetics }\end{array}$ \\
\hline $\begin{array}{l}\text { Living and working } \\
\text { conditions }\end{array}$ & $\begin{array}{l}\text { - Deprivation } \\
\text { - Health service supply and demand } \\
\text { - Deprivation concentration "area effects" } \\
\text { - Deindustrialization }\end{array}$ & $\begin{array}{l}\text { - Community safety } \\
\text { - Access to opportunities for physical activity } \\
\text { - Employment }\end{array}$ \\
\hline $\begin{array}{l}\text { Social and community } \\
\text { networks }\end{array}$ & $\begin{array}{l}\text { - Family, sex relations, and parenting differences } \\
\text { - Migration } \\
\text { - Lower "social capital" }\end{array}$ & $\begin{array}{l}\text { - Perceived community safety } \\
\text { - Perceived value to society }\end{array}$ \\
\hline Individual lifestyle factors & $\begin{array}{l}\text { - Health behaviors } \\
\text { - Different culture of substance misuse } \\
\text { - Individual values }\end{array}$ & $\begin{array}{l}\text { - Health literacy } \\
\text { - Psychological resilience and mental health } \\
\text { - Spiritual well-being } \\
\text { - Life-course effects } \\
\text { - Epigenetics }\end{array}$ \\
\hline $\begin{array}{l}\text { Age, sex, and constitutional } \\
\text { factors }\end{array}$ & - Genetic differences & $\begin{array}{l}\text { - Ethnicity } \\
\text { - Life-course effects } \\
\text { - Epigenetics }\end{array}$ \\
\hline
\end{tabular}

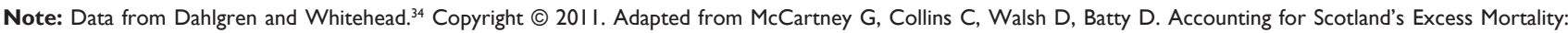
Towards a Synthesis. Glasgow: Glasgow Centre for Population Health. Available from: http://www.gcph.co.uk/publications/238accounting_for_scotlands_excess_mortality towards a synthesis.22

Abbreviation: GCPH, Glasgow Centre for Population Health. 
Key to the further exploration of this idea, however, is the need to understand, as recognized by Dahlgren and Whitehead, that no "level" of determinant exists in isolation, but that there is interplay between the levels. It may be that differences in the extent and nature of the interactions between these levels in Glasgow for many determinants of health, when compared to other cities, is as important as the impact of the individual determinants themselves. ${ }^{34}$

\section{The challenges of measurement}

Any review of this topic would be incomplete without some consideration of the difficulties encountered in measuring many of the factors under consideration. Measurement of almost any determinant in the Dahlgren and Whitehead model in order to derive its attributable risk, for example, presents significant challenges. If consideration is then given to the measurement of the interactions between determinants, the problem is even greater. To take deprivation as an example, Grundy and Holt described the complexities around accurate measurement of socioeconomic status, particularly among older people. ${ }^{38}$ They raised issues such as the logistic difficulties of collecting information on household income, the relevance of past occupation (among retired people) to current socioeconomic status, and the lack of applicability of household measures to older people living in institutions. ${ }^{38}$ Measuring the impact of an "individual" determinant such as socioeconomic status is therefore fraught with challenges. To fully understand socioeconomic status, a life-course approach may be more applicable (though even more complex to measure). ${ }^{39}$

In Glasgow, it is also of vital importance to consider historical events in terms of both societal-level events (such as deindustrialization) as well as individual-level/personal history (such as drug use in childhood) and their impact not only on society but also on individuals across their life course. ${ }^{10}$ This approach is in keeping with opinion expressed by Donnelly that it is important to consider adverse childhood experience and its health-damaging sequelae. ${ }^{40}$ Measuring such things and their effect in order to incorporate them into a causal pathway may not be achievable, and is certainly very difficult to do in the context of the kind of cross-sectional survey from which many of the associations with Glasgow's excess mortality have been described.

However, their measurement may not be the most important consideration in public health terms. In contrast to the other studies discussed here, a recent study by Levin using data from the cross-sectional 2006 Health Behaviour in School-Aged Children survey has shown that mental wellbeing among adolescents was better in Glasgow compared with the rest of Scotland. ${ }^{41}$ This suggests that the future life-course experience of current young Glaswegians has the potential to be very different from that of their forebears. It is also therefore true that public health efforts to change Glasgow's adverse health outcomes will take time to become evident (and to measure), though there is evidence of progress seen in interventions such as those reducing the levels of dental caries. ${ }^{42}$ Observable changes in later outcomes, including mortality, are likely to take longer. ${ }^{43}$ A particular focus is likely to be needed for younger people. There is good evidence from a study of the 31,648 suicides in England and Scotland between 2001 and 2006, for example, that the rate of suicide, particularly among young people, has been considerably higher in Scotland than in England (rate ratio $1.79,95 \%$ CI 1.62-1.98). ${ }^{44}$ Similarly, although numbers may be small in absolute terms, the contribution of drug use to Scotland's excess mortality among young people is important because of its high mortality risk. In a cohort study of 1,033 drug users across Scotland, Bloor et al estimated that, among people aged 15-54 years, drug use may account for 32\% (95\% CI 22.3\%-43.0\%) of Scotland's excess mortality. ${ }^{45}$ This reinforces the point made above about the ongoing need for public health (and societal) action in these areas.

Similarly, the measurement of other individual determinants such as "ethnicity" will include layers of complexity that are yet unexplored. Heterogeneity within ethnic groups, for example, may lead to differential impact on health-related behavior and outcomes such as cardiovascular mortality. ${ }^{46}$

Further unraveling the web of complexity around Glasgow's excess mortality may therefore include not only the need to consider the interplay of determinants in the Dahlgren and Whitehead model, but also to address the methodological issues around their measurement, to assess their relative influence, and to make adequate allowance for a life-course perspective. The effort required in this challenging task is, however, of great importance. An updated synthesis report is due to be produced by the GCPH in 2015 and will no doubt address many of these complex issues. ${ }^{47}$ As Gavine et al point out, continuing to understand the factors contributing to the "Glasgow effect" is necessary to accurately inform public health endeavors to improve the health outcomes and reduce health inequalities in Scotland; it should not slip into common parlance as an explanation in its own right. ${ }^{48}$

\section{Conclusion}

A comprehensive explanation of Glasgow's excess mortality remains elusive but is likely to lie in a complex and difficult-to-measure interplay of health determinants acting 
through the life course. It is an important example of the complexity that frequently lies behind health variations within and between populations. The research to date serves as an exemplar to usefully inform the critical evaluation of studies investigating morbidity and mortality variations in other countries and regions and the methodology of future study design in this area. Ongoing efforts to unravel its complexity are needed.

\section{Acknowledgments}

We are very grateful to David Walsh, Gerry McCartney, Anna Gavine, and Peter Donnelly for their assistance with the background to this article.

\section{Disclosure}

The authors declare that they have no conflicts of interest.

\section{References}

1. World Health Organisation Centre for Health Development. Hidden Cities: Unmasking and Overcoming Health Inequities in Urban Settings. WHO, Geneva, 2010. Available from: http://www.who.int/kobe_centre/ publications/hidden_cities2010/en/. Accessed February 24, 2015.

2. Europe's demographic future: facts and figures on challenges and opportunities. European Commission, Luxembourg, 2007. Available from: http://ec.europa.eu/social/main.jsp?catId=502\&furtherPubs=yes\& langId $=$ en\&pubId $=78 \&$ type $=2$. Accessed February 24, 2015.

3. Leon DA, Morton S, Cannegieter S, McKee M. Understanding the Health of Scotland's Population in an International Context; A review of current approaches, knowledge and recommendations for new research directions. London School of Hygiene and Tropical Medicine, London, 2003. Available from: http://www.google.co.uk/url?sa=t\&rct=j\&q=\&e $\mathrm{src}=\mathrm{s} \&$ source $=$ web $\& \mathrm{~cd}=1 \& \mathrm{ved}=0 \mathrm{CCMQFjAA} \&$ url $=\mathrm{http} \% 3 \mathrm{~A} \% 2 \mathrm{~F} \%$ 2Fwww.scotpho.org.uk\%2Fdownloads\%2Fscotphoreports\%2Fscotph o061107_leonreport.doc\&ei=4HrsVNSgDJHTaL2qguAC\&usg=AFQ jCNEezJlEDp5Ueita0rSYbo_TAd4KNQ\&bvm=bv.86475890,d.d2s. Accessed February 24, 2015.

4. Carstairs V, Morris R. Deprivation: explaining differences in mortality between Scotland and England and Wales. BMJ. 1989;299(6704): 886-889.

5. Scottish Council Foundation, Healthy Public Policy Network. The Scottish Effect? Edinburgh: Scottish Council Foundation; 1998.

6. Hanlon P, Walsh D, Buchanan D, et al. Chasing the Scottish Effect: Why Scotland Needs a Step-Change in Health if it is to Catch Up with the Rest of Europe. Glasgow: Public Health Institute of Scotland; 2001.

7. Gray L, Merlo J, Mindell J, et al. International differences in selfreported health measures in 33 major metropolitan areas in Europe. Eur J Public Health. 2012;22(1):40-47.

8. Hanlon P, Lawder RS, Buchanan D, et al. Why is mortality higher in Scotland than in England and Wales? Decreasing influence of socioeconomic deprivation between 1981 and 2001 supports the existence of a "Scottish Effect". J Public Health. 2005;27(2):199-204.

9. Walsh D, Bendel N, Jones R, Hanlon P. It's not "just deprivation": why do equally deprived UK cities experience different health outcomes? Public Health. 2010;124(9):487-495.

10. Walsh D, Taulbut M, Hanlon P. The aftershock of deindustrializationtrends in mortality in Scotland and other parts of post-industrial Europe. Eur J Public Health. 2010;20(1):58-64.

11. Gray L. Comparisons of Health-Related Behaviours and Health Measures between Glasgow and the Rest of Scotland. Glasgow: Glasgow Centre for Population Health, Briefing Paper 7; 2007.
12. Gray L. Comparisons of Health-Related Behaviours and Health Measures in Greater Glasgow with Other Regional Areas in Europe. Glagow: Glasgow Centre for Population Health; 2008.

13. Carstairs V, Morris R. Deprivation and health in Scotland. Health Bull (Edinb). 1990;48(4):162-175.

14. Gray L, Leyland AH. Is the "Glasgow effect" of cigarette smoking explained by socio-economic status?: a multilevel analysis. BMC Public Health. 2009;9:245.

15. Gray L, Leyland AH. A multilevel analysis of diet and socio-economic status in Scotland: investigating the "Glasgow effect". Public Health Nutr. 2009;12(9):1351-1358.

16. George S. It's not just deprivation - or is it? Public Health. 2010; 124(9): 496-497.

17. The Scottish Health Survey Topic Report. The Glasgow Effect. The Scottish Government, Edinburgh, 2010. Available from: http://www.scotland.gov. uk/Publications/2010/11/10110338/0. Accessed February 24, 2015.

18. Fischbacher CM, Steiner M, Bhopal R, et al. Variations in all cause and cardiovascular mortality by country of birth in Scotland, 1997-2003. Scott Med J. 2007;52(4):5-10.

19. Popham F, Boyle PJ, Norman P. The Scottish excess in mortality compared to the English and Welsh. Is it a country of residence or country of birth excess? Health Place. 2010;16(4):759-762.

20. Popham F, Boyle PJ, O'Reilly D, Leyland AH. Selective internal migration. Does it explain Glasgow's worsening mortality record? Health Place. 2011;17(6):1212-1217.

21. Hill A. The environment and disease: association or causation? Proc R Soc Med. 1965;58:295-300.

22. McCartney G, Collins C, Walsh D, Batty D. Accounting for Scotland's Excess Mortality: Towards a Synthesis. Glasgow: Glasgow Centre for Population Health; 2011. Available from: http://www.gcph. co.uk/publications/238accounting_for_scotlands_excess_mortality_towards_a_synthesis. Accessed May 28th 2015.

23. Rothman KJ. Modern Epidemiology. Boston, MA: Little, Brown and Company; 1986:7-28.

24. Collins C, McCartney G. The impact of neoliberal "political attack" on health: the case of the "Scottish effect". Int J Health Serv. 2011;41(3): 501-523.

25. Navarro V, Shi L. The political context of social inequalities and health. Soc Sci Med. 2001;52(3):481-491.

26. Walsh D, Taulbut M, Hanlon P. The Aftershock of Deindustrialisation: Trends in Mortality in Scotland and Other Parts of Post-Industrial Europe. Glasgow: Glasgow Centre for Population Health; 2008.

27. Chandola T. Spatial and social determinants of urban health in low-, middle- and high-income countries. Public Health. 2012;126(3): 259-261.

28. Livingston M, Lee D. "The Glasgow effect?" - the result of the geographical patterning of deprived areas? Health Place. 2014;29: $1-9$.

29. Taulbut M, Walsh D, McCartney G, et al. Spatial inequalities in life expectancy within postindustrial regions of Europe: a cross-sectional observational study. BMJ Open. 2014;4(6):e004711.

30. Rush L, McCartney G, Walsh D, MacKay D. Vitamin D and subsequent all-age and premature mortality: a systematic review. BMC Public Health. 2013;13:679. doi: 10.1186/1471-2458-13-679.

31. Graham P, Walsh D, McCartney G. Shipyards and sectarianism: how do mortality and deprivation compare in Glasgow and Belfast? Public Health. 2012;126(5):378-385. doi: 10.1016/j.puhe.2012.01.018.

32. Taulbut M, Walsh D, O'Dowd J. Comparing early years and childhood experiences and outcomes in Scotland, England and three city-regions: a plausible explanation for Scottish "excess" mortality? BMC Pediatr. 2014;14:259. doi: 10.1186/1471-2431-14-259.

33. Walsh D, McCartney G, McCullough S, Buchanan D, Jones R. Comparing Antonovsky's sense of coherence scale across three UK post-industrial cities. BMJ Open. 2014;4(11):e005792. doi: 10.1136/ bmjopen-2014-005792.

34. Dahlgren G, Whitehead M. Policies and Strategies to Promote Social Equity in Health. Stockholm: Institute of Futures Studies; 1991. 
35. Breitling LP. Current genetics and epigenetics of smoking/tobaccorelated cardiovascular disease. Arterioscler Thromb Vasc Biol. 2013;33: 1468-1472.

36. McGuinness D, McGlynn LM, Johnson PC, et al. Socio-economic status is associated with epigenetic differences in the pSoBid cohort. Int J Epidemiol. 2012;41(1):151-160.

37. McCartney G, Russ TC, Walsh D, et al. Explaining the excess mortality in Scotland compared with England: pooling of 18 cohort studies. J Epidemiol Community Health. 2015;69(1):20-27.

38. Grundy E, Holt G. The socioeconomic status of older adults: how should we measure it in studies of health inequalities? J Epidemiol Community Health. 2001;55:895-904.

39. Chittleborough CR, Baum FE, Taylor AW, Hiller JE. A life-course approach to measuring socioeconomic position in population health surveillance systems. J Epidemiol Community Health. 2006;60(11): 981-992.

40. Donnelly PD. Explaining the Glasgow effect: could adverse childhood experiences play a role? Public Health. 2010;124:498-499.

41. Levin KA. Glasgow smiles better: an examination of adolescent mental well-being and the "Glasgow effect". Public Health. 2012;126(2): 96-103.
42. McMahon AD, Blair Y, McCall DR, Macpherson LM. Reductions in dental decay in 3-year old children in Greater Glasgow and Clyde: repeated population inspection studies over four years. BMC Oral Health. 2011;11:29.

43. Reid M. Behind the "Glasgow effect". Bull World Health Organ. 2011; 89:706-707.

44. Mok PL, Leyland AH, Kapur N, et al. Why does Scotland have a higher suicide rate than England? An area-level investigation of health and social factors. J Epidemiol Community Health. 2013;67(1):63-70.

45. Bloor M, Gannon M, Hay G, Jackson G, Leyland AH, McKeganey N. Contribution of problem drug users' deaths to excess mortality in Scotland: secondary analysis of cohort study. BMJ. 2008;337:a478.

46. Bhopal RS. Heterogeneity among Indians, Pakistanis, and Bangladeshis is key to racial inequities. BMJ. 2002;325(7369):903.

47. Glasgow Centre for Population Health. Work themes. Available from: http://www.gcph.co.uk/work_themes/synthesis_what_have_we_ learned. Accessed March 25, 2015.

48. Gavine AJ, Williams DJ, Shearer MC, Donnelly PD. The Glasgow effect: useful construct or epidemiological dead end? Public Health. 2011;125(8):561-562.

\section{Publish your work in this journal}

Risk Management and Healthcare Policy is an international, peerreviewed, open access journal focusing on all aspects of public health, policy, and preventative measures to promote good health and improve morbidity and mortality in the population. The journal welcomes submitted papers covering original research, basic science, clinical \& epidemio-

\section{Dovepress}

logical studies, reviews and evaluations, guidelines, expert opinion and commentary, case reports and extended reports. The manuscript management system is completely online and includes a very quick and fair peerreview system, which is all easy to use. Visit http://www.dovepress.com/ testimonials.php to read real quotes from published authors. 